Article

\title{
Pre-Anodized Graphite Pencil Electrode Coated with a Poly(Thionine) Film for Simultaneous Sensing of 3-Nitrophenol and 4-Nitrophenol in Environmental Water Samples
}

\author{
Vijaya Gopalan Sree *(D), Jung Inn Sohn and Hyunsik Im
}

Citation: Sree, V.G.; Sohn, J.I.; Im, H. Pre-Anodized Graphite Pencil Electrode Coated with a Poly(Thionine) Film for Simultaneous Sensing of 3-Nitrophenol and 4-Nitrophenol in Environmental Water Samples. Sensors 2022, 22, 1151 https://doi.org/10.3390/s22031151

Academic Editors: Matjaž Finšgar and Tinkara Mastnak

Received: 9 January 2022

Accepted: 30 January 2022

Published: 2 February 2022

Publisher's Note: MDPI stays neutral with regard to jurisdictional claims in published maps and institutional affiliations.

Copyright: (C) 2022 by the authors. Licensee MDPI, Basel, Switzerland. This article is an open access article distributed under the terms and conditions of the Creative Commons Attribution (CC BY) license (https:// creativecommons.org/licenses/by/ $4.0 /$ )

\author{
Division of Physics and Semiconductor Science, Dongguk University, Seoul 04620, Korea; \\ junginn.sohn@dongguk.edu (J.I.S.); hyunsik7@dongguk.edu (H.I.) \\ * Correspondence: sreevg@dgu.ac.kr
}

\begin{abstract}
A very simple, as well as sensitive and selective, sensing protocol was developed on a pre-anodized graphite pencil electrode surface coated using poly(thionine) (APGE/PTH). The poly(thionine) coated graphite pencil was then used for simultaneous sensing of 3-nitrophenol (3-NP) and 4-nitrophenol (4-NP). The poly(thionine) coated electrode exhibited an enhanced electrocatalytic property towards nitrophenol (3-NP and 4-NP) reduction. Redox peak potential and current of both nitrophenols were found well resolved and their simultaneous analysis was studied. Under optimized experimental conditions, APGE/PTH showed a long linear concentration range from 20 to $230 \mathrm{nM}$ and $15 \mathrm{nM}$ to $280 \mathrm{nM}$ with a calculated limit of detection (LOD) of 4.5 and $4 \mathrm{nM}$ and a sensitivity of $22.45 \mu \mathrm{A} / \mathrm{nM}$ and $27.12 \mu \mathrm{A} / \mathrm{nM}$ for 3-NP and 4-NP, respectively. Real sample analysis using the prepared sensor was tested with different environmental water samples and the sensors exhibited excellent recovery results in the range from 98.16 to $103.43 \%$. Finally, the sensor exposed an promising selectivity, stability, and reproducibility towards sensing of 3-NP and 4-NP.
\end{abstract}

Keywords: pencil graphite electrode; pre-anodization; poly(thionine); 3-nitrophenol; 4-nitrophenol; water samples

\section{Introduction}

The U.S environmental protection agency (USEPA) classified that the nitroaromatic compounds (2-nitrophenol, 3-nitrophenol, and 4-nitrophenol) are environmentally hazardous materials due to their harmful nature, where even low-level concentrations can affect living organisms including humans, animals, and plants [1-4]. When these nitrophenol isomers enter the human body, they can cause several health problems such as headaches, drowsiness, fever, and methemoglobinemia [5,6]. Moreover, these compounds severely affect plants' growth through water contamination $(0.7 \mathrm{mM} / \mathrm{L}$ of nitrophenols $)$ [7]. However, huge quantities of nitrophenols are used in various industries such as pharmaceuticals, pesticides, dyes, and explosives [8-10], leading to nitrophenol isomers being present not just in water sources but also in soil samples. In particular, nitrophenols are largely found in different kinds of environmental water samples due to their easy solubility and high stability in aqueous media. These compounds are degradable due to the presence of strong electron-withdrawing species which produce an unpleasant smell and bitter taste, thus greatly affecting the environment of aquatic living species [11-13]. Therefore, the maximum allowed concentration level of these nitrophenols in the drinking water is 0.5-5 $\mathrm{MM} / \mathrm{L}[14,15]$. Nitrophenol isomers constantly react and influence other phenolic compounds due to their structural similarity and physio-chemical nature [16,17]. Hence, sensing of these nitrophenol isomers in environmental water samples is an essential task.

Different analytical methods such as spectrometry [18,19], high-performance liquid chromatography with different detectors [20,21], capillary electrophoresis [22], flow injection detection [23], fluorescence [24,25], surface-enhanced Raman spectroscopy (SERS) [26], 
and chemiluminescence $[27,28]$ have been used to quantify these nitrophenol isomers. However, common analysis procedures take a long time and are highly expensive, requiring sophisticated instrumentation facility with samples that were pre-treated [29]. Among these techniques, the electrochemical analysis has been considered an outstanding and alternative method for nitrophenol quantification, several advantages such as an easy method of sample preparation, simple and continuous steps for sample analysis, and rapid output response [30,31]. Moreover, these analytical instruments are portable and low-cost, making them uncomplicated and suitable for onsite monitoring.

Recently, different kinds of nanomaterials and conductive polymer-based modified materials have been used for simultaneous and individual sensing of nitrophenol isomers [32,33]. Nanomaterials and polymers improve the electrocatalytic property as well as the surface area of the modified electrodes to achieve high sensitivity and selectivity of the nitrophenols [34,35]. Compared to the nanomaterial-based modified materials, polymer-based materials have massive advantages recently due to their high stability, interlinking the different active sides [35], and uniformity during the electrochemical deposition/polymerization with robust adherence on the electrode surface [36]. Electropolymerization/deposition is highly advantageous in securing the polymer on the electrode surface. The polymer film width, pervasion, and charge transfer characteristic can be controlled simply by tuning the electroanalytical optimization conditions $[37,38]$. The highly redox-active polymer of poly(thionine) has been coated on different kinds of the electrode surfaces and then used in various electrochemical sensing applications such as pre-treated glassy carbon electrode (GCE) coated with poly(thionine) for sensitive detection of dopamine [39], poly(thionine)/gold composite coated on ITO electrode for label-free detection of DNA hybridization [40], poly(thionine)/CuO nanoparticles coated pencil for paracetamol sensing in the presence of ascorbic acid [41], poly(thionine) coated on a carbon screen-printed electrode for flow-injection method analysis of NADH [42], and carbon nanotube/poly(thionine) modified carbon film electrode for simultaneous sensing of acetaminophen and dipyrone [43]. Poly(thionine) has exhibited excellent electrocatalytic activity in the detection of neurotransmitters, hydroxy benzenes, and other biologically important molecules [44-46]. However, poly(thionine) used for hydrogen peroxide reduction in different food and cosmetic samples has also been reported [47,48]. Herein, a new analytical protocol for poly(thionine) formation on pre-anodized pencil graphite electrodes is developed to show the enhanced electrocatalytic reduction of 3-nitrophenol and 4-nitrophenol. However, the 2-nitrophenols were not detected due to their intramolecular hydrogen bonding through the $-\mathrm{OH}$ and $-\mathrm{NO}_{2}$ moieties that were present in the nearby position at the benzene ring $[49,50]$. Therefore, APGE/PTH has been utilized for the electrocatalytic sensing of 3-NP and 4-NP and provided an excellent electrochemical response in different environmental water samples.

In this work, poly(thionine) (PTH) coated on a pre-anodized graphite pencil electrode (APGE) was used to study the electrocatalytic behavior towards selective reduction of 3-NP and 4-NP. The APGE/PTH has shown that these two nitrophenols were individually and effectively separated and, their simultaneous sensing was also tested. The proposed sensing material has shown an excellent catalytic activity, high sensitivity, well-defined peak separations, long-term stability, and reproducibility.

\section{Materials and Methods}

\subsection{Chemicals and Reagents}

The analytical grade of chemicals such as 2-nitrophenol, 3-nitrophenol, 4-nitrophenols, thionine, catechol, $\mathrm{K}_{2} \mathrm{HPO}_{4}$, and $\mathrm{KH}_{2} \mathrm{PO}_{4}$ were bought from Sigma-Aldrich (USA). Other reagents purchased were of analytical reagent quality without extra purification. Phosphate buffer saline ( $0.1 \mathrm{M}, \mathrm{PBS})$ was prepared by mixing $\mathrm{K}_{2} \mathrm{HPO}_{4}$ and $\mathrm{KH}_{2} \mathrm{PO}_{4}$ solutions followed by altering the $\mathrm{pH}$ with sodium hydroxide $(\mathrm{NaOH})$ or phosphoric acid $\left(\mathrm{H}_{3} \mathrm{PO}_{4}\right)$. All the target analytes' (3-NP and 4-NP) stack solutions $(0.01 \mathrm{mM})$ were prepared with deionized water. All the stock solutions were placed in a black place to eliminate the direct contact of 
sunlight. All the aqueous solutions used for the electrochemical experiment were prepared using double distilled water that was collected from the Milli-Q water cleansing chamber $(18.2 \mathrm{M} \Omega \mathrm{cm})$. All electrochemical experiments were carried out at room temperature $\left(26 \pm 1^{\circ} \mathrm{C}\right)$ and purified inert nitrogen gas was purged in the electrolyte for $300 \mathrm{~s}$ before electrochemical measurements.

\subsection{Instruments}

The electroanalytical measurements were carried out using a $\mathrm{CHI} 660 \mathrm{~B}$ potentiostat (CH Instruments Inc., Austin, TX, USA) with a portable three-electrode assembly. Pencil graphite $\left(2.4 \mathrm{~mm} \times 40 \mathrm{~mm}\right.$ with disc area of $\left.0.044 \mathrm{~cm}^{2}\right)(\mathrm{PGE})$, pre-anodized pencil graphite electrode (APGE), and pre-anodized pencil graphite electrode on the poly(thionine) (APGE/PTH) electrode were used for the working electrodes and, platinum wire and silver/silver chloride $(3 \mathrm{M} \mathrm{KCl})$ were used as auxiliary and reference electrodes, respectively. All potentials were measured using this reference electrode. Electrochemical impedance spectroscopy (EIS) measurements were carried out in the frequency range from $0.1 \mathrm{~Hz}$ to $100 \mathrm{kHz}$ in $5 \mathrm{mmol} / \mathrm{L}$ of $\mathrm{K}_{3 / 4}\left[\mathrm{Fe}(\mathrm{CN})_{6}\right]$ in $0.1 \mathrm{~mol} / \mathrm{L}$ of $\mathrm{KCl}$ solution with the following EIS amplitude of $5 \mathrm{mV}$ and AC bias of $0.26 \mathrm{~V}$. The functional group of APGE and APGE/PTH electrodes were confirmed using FT-IR spectra obtained from JASCO FT-IR4600 (Tokyo, Japan).

\subsection{Fabrication of APGE and APGE/PTH}

Four HB pencils were collected from the local stationery shop and the pencils' wooden parts were removed with a sharp knife (Figure S1). The pencils' graphite rods were cleaned with ethanol and water and were then allowed to dry. The graphite rods had some micropores and cavities. Hence, to prevent these micropores, paraffin wax was impregnated on the cavity surface following our previously reported method [51]. In brief, one end of pencil graphite rod surface was polished with different qualities (500 and 600 grade) of the emery paper, and finally, the smoothed surface was washed with ethanol and deionized water. The cleaned graphite rods were kept in an electrochemical cell comprising $0.1 \mathrm{M}$ PBS followed by pre-anodization by applying $1.8 \mathrm{~V}$ for $300 \mathrm{~s}$ on the working electrode. APGE/PTH was fabricated and measured by sweeping the potential from -0.4 to $0.1 \mathrm{~V}$ with a scan rate of $50 \mathrm{mV} / \mathrm{s}$ in $0.1 \mathrm{M}$ PBS containing $0.5 \mathrm{mmol} / \mathrm{L}$ of thionine (Figure S2). PTH coated on APGE was washed with deionized water to remove unreacted thionine monomers. Finally, a dark blue color was observed which might be due to the PTH on the surface of the electrode [39].

\section{Results and Discussion}

\subsection{Surface Morphology and FT-IR Measurements of APGE and APGE/PTH}

The scanning electron microscopic images of the pencil graphite rod, pre-anodized pencil graphite rod, and poly(thionine)-coated pencil graphite rod electrodes are illustrated in Figure 1. A typical rough surface was observed on the pencil graphite rod (Figure 1A). The pre-anodized graphite pencil rod exhibited mesoporous flack-type morphology and the morphological changes confirm that the $-\mathrm{OH}$ and $-\mathrm{COOH}$ groups were attached on the surface of the graphite rod (Figure 1B). From Figure 1C,D, it is clear that the graphite flacks were covered with a polymer film (the rod-like structures) confirming the film formation on the electrode surface. Hence, these surface morphological studies confirm that poly(thionine) was directly linked on the graphite electrode surface. Previously, it has been reported that the preanodization of carbon electrodes creates oxygen rich functional groups, such as carbonyl, phenolic, alcoholic, carboxylic and ether, on its outer surface and further helps the promotion of the electron oxidation/reduction of certain small molecules and bio-chemicals [52]. To confirm the surface functional groups, APGE and APGE/PTH were studied by FT-IR spectral method. Figure 2A shows that the APGE electrode has broad stretching vibration of $-\mathrm{OH}$ at $3274 \mathrm{~cm}^{-1}, \mathrm{sp}^{2}$ carbon $(=\mathrm{CH}=\mathrm{CH}=)$ stretching vibrations (breathing mode) at $1635 \mathrm{~cm}^{-1}$ and the symmetric and unsymmetric 
stretching mode of $=\mathrm{CH}_{2}$ at $2186 \mathrm{~cm}^{-1}$ [52]. Further, PTH coated on the APGE surface showed significant vibration for primary amine (-N-H) stretching at 3670, 2990, 2900, and $3360 \mathrm{~cm}^{-1}$ followed by $1600 \mathrm{~cm}^{-1}$ corresponding to the C-S bond stretching [53]. Hence, FT-IR spectral studies confirmed that the $-\mathrm{OH}$ and $-\mathrm{COO}-$ moieties were present on the APGE surface. Additionally, electrochemical polymerization of PTH on the APGE surface was also confirmed.
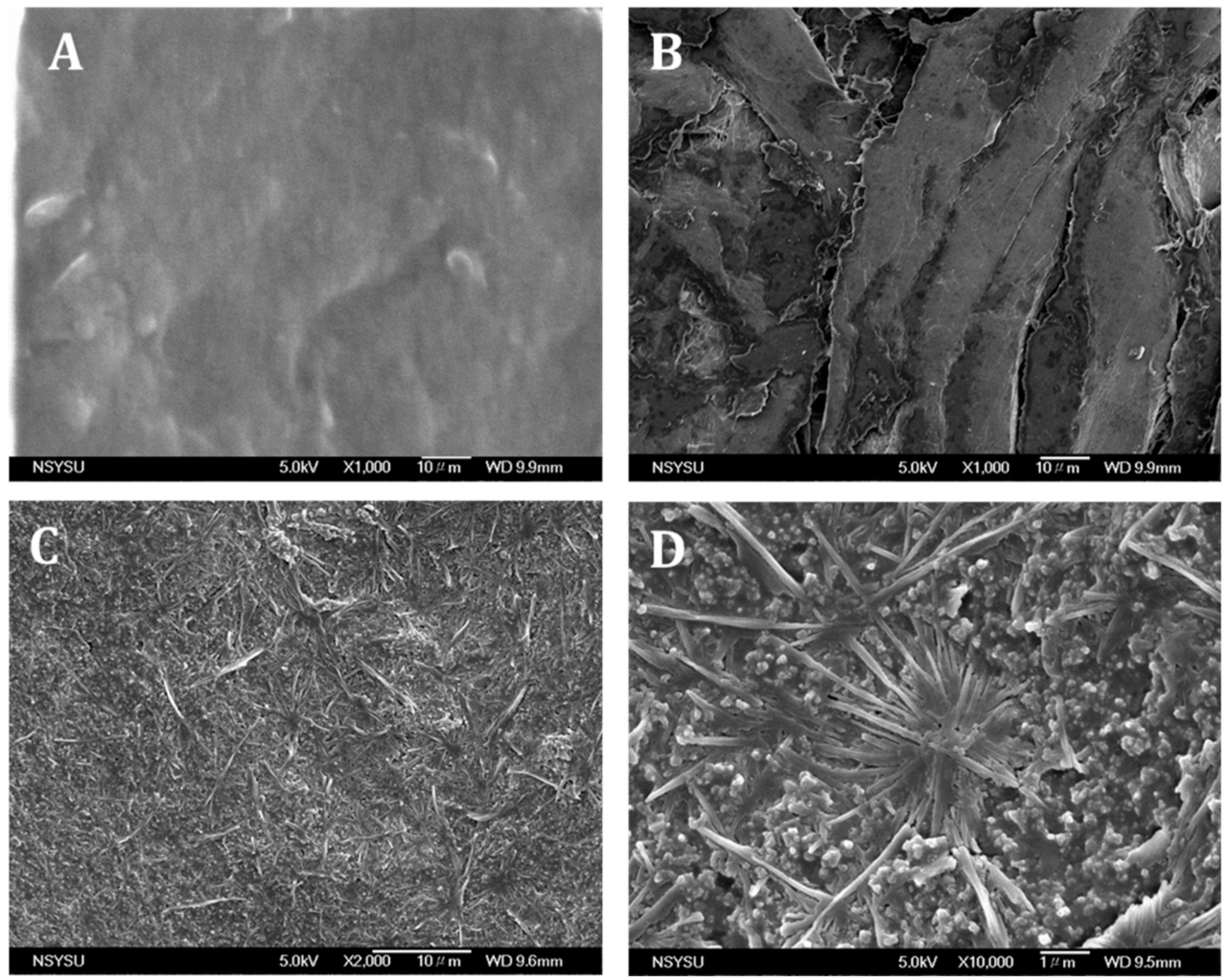

Figure 1. SEM images of (A) pencil graphite rod, (B) Pre-anodized pencil graphite rod, (C,D) Poly(thionine) on the pre-anodized pencil graphite rod with different magnifications.

\subsection{Electrochemical Characterization of APGE/PTH}

The surface characteristics of the fabricated APGE and APGE/PTH were studied using the $\mathrm{CV}$ and EIS methods. Figure 2B illustrates $\mathrm{CV}$ responses of the electrodes PGE, APGE, and APGE/PTH in $5 \mathrm{mmol} / \mathrm{L}$ of $\mathrm{K}_{3 / 4}\left[\mathrm{Fe}(\mathrm{CN})_{6}\right] 0.1 \mathrm{M}$ of $\mathrm{KCl}$ at a scan rate of $50 \mathrm{mV} / \mathrm{s}$. The peak-to-peak separation of the three electrodes was estimated to be $0.10,0.14$, and $0.07 \mathrm{mV}$, corresponding to PGE, APGE, and APGE/PTH, respectively. APGE showed broad redox peaks with lower current response in the $\mathrm{K}_{3 / 4}\left[\mathrm{Fe}(\mathrm{CN})_{6}\right]$ electrolyte, confirming that the electrode surface has negatively charged species such as hydroxyl and carboxyl groups. These negatively charged groups undergo electrostatic repulsion between the electrode surface and electrolyte solution [39]. Furthermore, with the modified PTH on the APGE surface, the redox peak current was enhanced and a lower $\Delta \mathrm{Ep}$ value was achieved. The lower $\triangle \mathrm{Ep}$ indicates that APGE/PTH has a facetious electron movement property of the electrode. Based on Randles-Sevick equation [54],

$$
i p c=2.69 \times 105 \text { Ae } D 1 / 2 n 3 / 2 v 1 / 2 c
$$

where $n$ represents the quantity of electron transfer in the redox couple, $D$ represents the diffusion coefficient $\left(7.6 \times 10^{-6} \mathrm{~cm}^{2} \mathrm{~s}^{-1}\right), c$ represents the concentration of the redox couple, and Ae represents the electroactive available surface area. Here, Ae was estimated to be $0.0732,0.0976$, and $0.1235 \mathrm{~cm}^{2}$ corresponding to the PGE, APGE, and APGE/PTH, respectively. At the same time, electrochemical impedance spectral (EIS) measurements 
were studied in $0.1 \mathrm{M} \mathrm{KCl}$ containing $5 \mathrm{mmol} / \mathrm{L}$ of $\mathrm{K}_{3 / 4}\left[\mathrm{Fe}(\mathrm{CN})_{6}\right]$ as a redox probe with a bias voltage of $0.19 \mathrm{~V}$ vs. Ag/AgCl. Figure 2C shows the EIS response of (Nyquist graph of $Z^{\prime}$ vs. $\left.-Z^{\prime \prime}\right)$ PGE, APGE, and APGE/PTH. All the obtained EIS data were fitted with Randle's equivalent circuit (Figure 1C-inset). From the Randle's equivalent circuit, charge transfer resistance $\left(R_{c t}\right)$, and Warburg impedance $\left(Z_{\mathrm{w}}\right)$ are side by side to double layer capacitance $\left(\mathrm{C}_{\mathrm{dl}}\right)$. The half-circle diameter is matched with the $R_{c t}$ value which indicates that the electron transfer process in the redox species is in the interface between the electrode and electrolyte [52]. PGE in the Nyquist graph form showed a semicircle with an $R_{c t}$ of $750 \Omega$, and APGE showed large semicircle with an $R_{c t}$ of $8000 \Omega$. This large semicircle is due to the repulsion between the pre-anodized electrode that has negatively charged hydroxyl and carboxyl groups that undergoes electrostatic repulsion between the electrolyte and electrode. At the same time APGE/PTH showed a lower semicircle with an $R_{c t}$ of $180 \Omega$. Based on the $R_{c t}$ values, the switched current density (jo) was calculated for all the three different kinds of electrodes using the following equation [55]

$$
j o=R T / n F A R_{c t}
$$

The $R$ represents gas constant $(8.314 \mathrm{~J} / \mathrm{K} / \mathrm{mol}) ; T$, the ambient temperature $(298 \mathrm{~K})$; $n$, the quantity of electrons transferred through the redox reaction $(1) ; F$, the Faraday constant $(96,485 \mathrm{C} / \mathrm{mol})$; and $A$, the surface area of the electrode $\left(0.04 \mathrm{~cm}^{2}\right)$. The obtained jo values were $0.0123,0.0032$, and $0.2128 \mathrm{~A} \mathrm{~cm}^{-2}$ for PGE, APGE, and APGE/PTH, respectively. Compared to other electrodes, the APGE/PTH coated electrode showed an almost three-times-higher value. Hence, with lowest obtained $R_{c t}$ (EIS response), as well as higher jo values, it is clear that APGE/PTH exhibits excellent electrochemical behaviors that are advantageous for the electrochemical experiments [55-57].
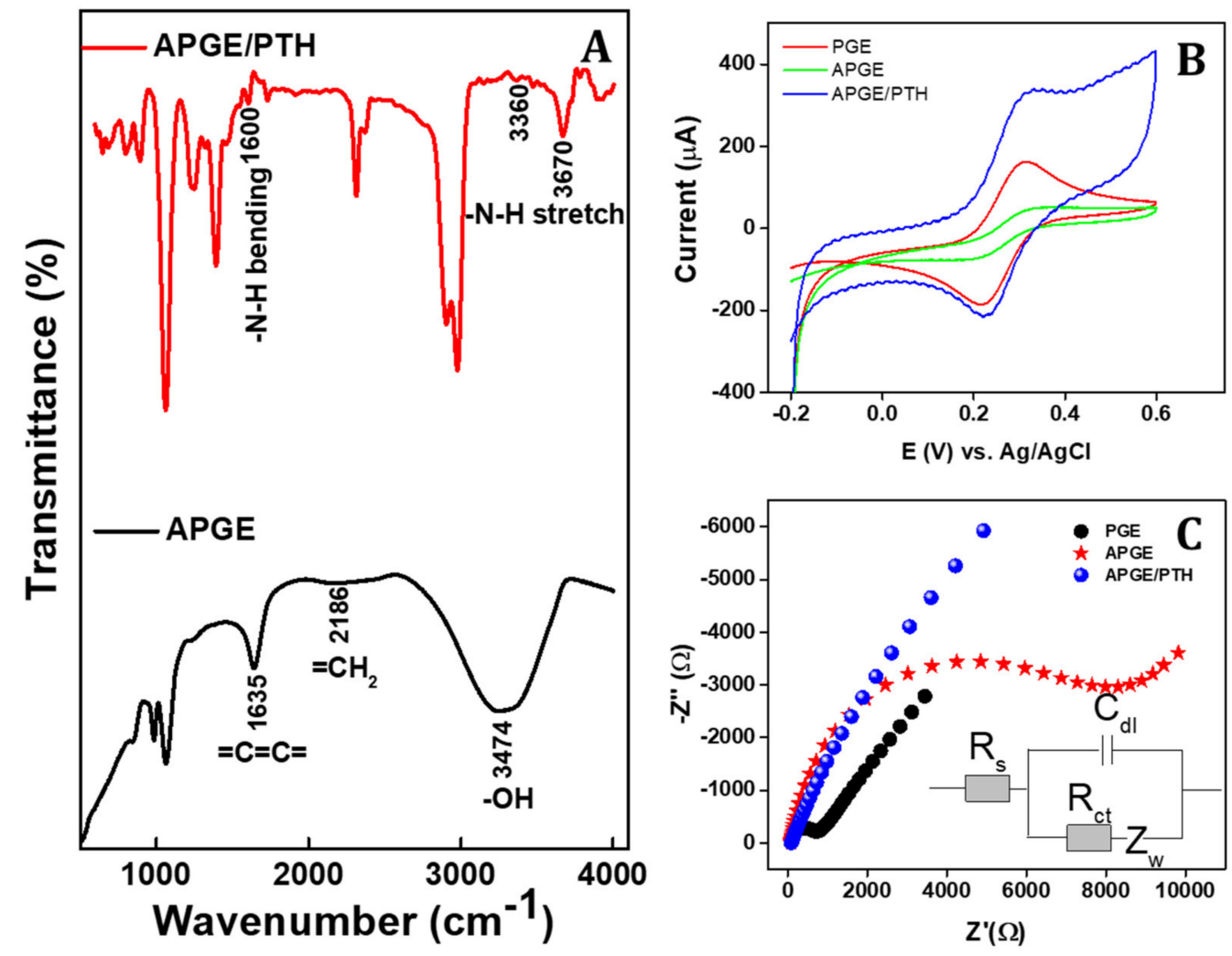

Figure 2. (A) FT-IR spectra of the APGE and APGE/PTH, (B) electrochemical CV response of different electrodes in $5 \mathrm{mmol} / \mathrm{L}_{3 / 4}\left[\mathrm{Fe}(\mathrm{CN})_{6}\right]$ in $0.1 \mathrm{M} \mathrm{KCl}$ with scan rate of $50 \mathrm{mV} / \mathrm{s}$ and (C) EIS response of the different electrodes in $5 \mathrm{mmol} / \mathrm{L}$ of $\mathrm{K}_{3 / 4}\left[\mathrm{Fe}(\mathrm{CN})_{6}\right]$ in $0.1 \mathrm{M} \mathrm{KCl}$ at Eapp is $0.18 \mathrm{~V}$ vs. $\mathrm{Ag} / \mathrm{AgCl}$ (inset figure, Randles equivalent circuit). 


\subsection{Optimization of PTH on the APGE towards Sensing of 3-NP and 4-NP}

A different series of cyclic voltammograms were studied for the optimization of poly(thionine) formation on the APGE surface. The poly(thionine) thickness was directly connected with the number of sweeping segments throughout the electrochemical polymerization [39]. The poly(thionine) film thickness was thus studied by numerous polymerization cycles on the sensing of 3-NP and 4-NP. The PTH was prepared via the electrochemical polymerization technique on the pre-anodized graphite electrode in $0.1 \mathrm{M}$ PBS in $0.5 \mathrm{mmol} / \mathrm{L}$ of thionine and a cycling range from 5 to 40 with a scan rate of $50 \mathrm{mV} / \mathrm{s}$. Figure 3A shows the different forms of electrocatalytic behavior of PTH with a different number of sweeping cycles. The redox peak and cathodic current were increased after increasing the number of sweeping segments up to 30 cycles. After 30 cycles, the cathodic peak current decreased slightly. This behavior demonstrates the activity of PTH at certain thickness levels and electron transfer of the polymer thickness barrier [58]. Hence, 30 sweeping cycles was chosen as the optimum condition for the electrocatalytic sensing of 3-NP and 4-NP.
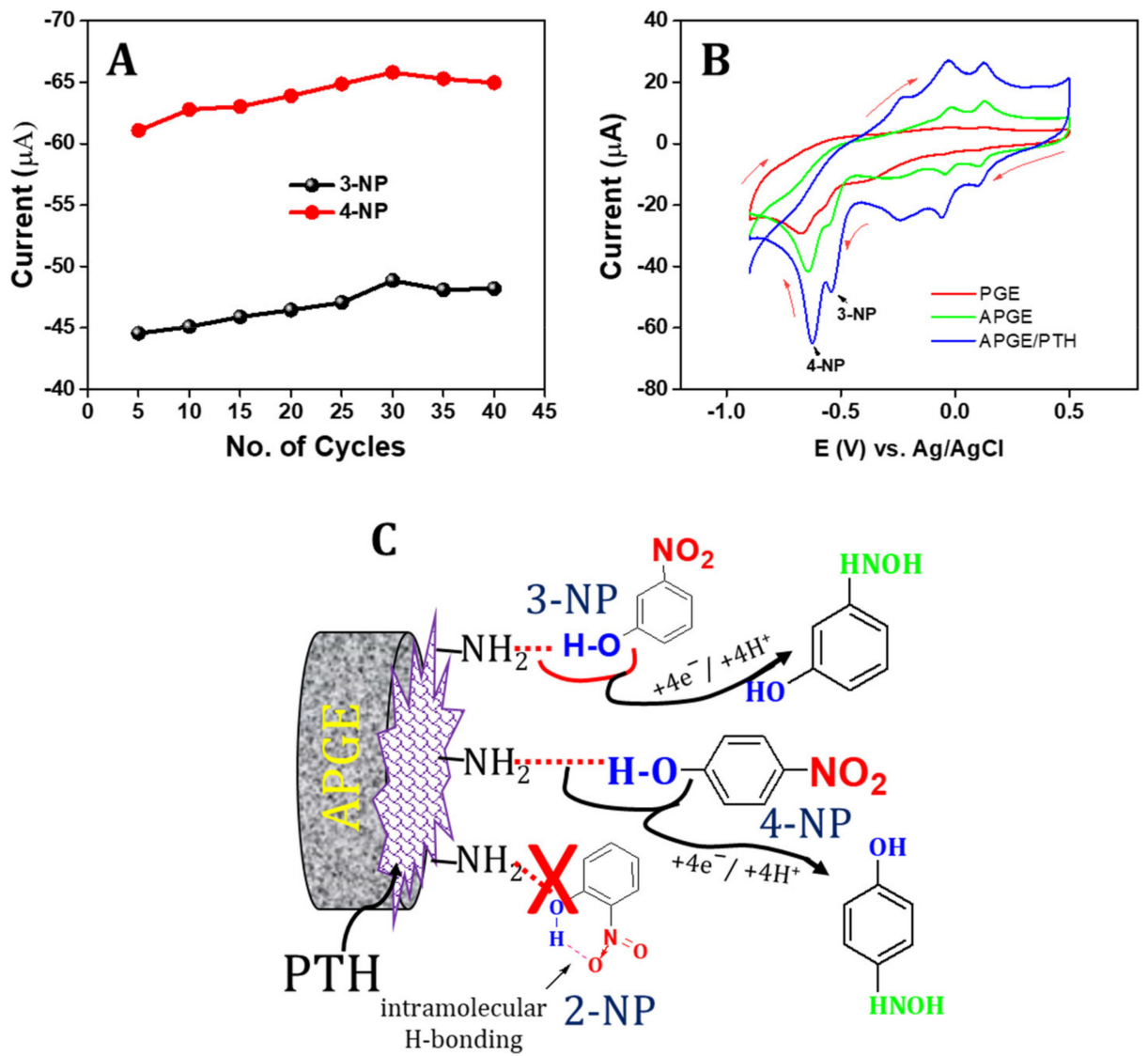

Figure 3. (A) The cathodic peak current dependence of 3-NP and 4-NP (20 $\mu \mathrm{M}$ of each) on the number of cycles of the cyclic voltammogram during the thionine electrochemical polymerization, (B) Cyclic voltametric response of the different modified electrodes in $0.1 \mathrm{M}$ PBS containing $20 \mu \mathrm{M}$ of 3-NP and 4-NP at scan rate of $50 \mathrm{mV} / \mathrm{s}$ and (C) Schematic representation of the proposed mechanism for sensing of 3-NP and 4-NP at APGE/PTH via hydrogen bond formation.

\subsection{Electrocatalytic Behavior of APGE/PTH towards Sensing of 3-NP and 4-NP}

The electrocatalytic behavior of the fabricated APGE/PTH electrode towards the sensing of 3-NP and 4-NP was studied using cyclic voltammetry. Figure 3B shows cyclic voltammetry results for $0.1 \mathrm{mmol} / \mathrm{L}$ of 3-NP and 4-NP for unmodified PGE, APGE, and APGE/PTH modified electrodes. For the unmodified PGE, the redox peaks of 3-NP and 4-NP were observed at $0.13 / 0.09 \mathrm{~V}$ and $-0.01 /-0.04 \mathrm{~V}$ with reduction potentials 
of -0.58 and $-0.60 \mathrm{~V}$, respectively. The calculated peak-to-peak separations $(\Delta \mathrm{Ep})$ were $0.04 \mathrm{~V}$ and $0.03 \mathrm{~V}$, and nitrophenol isomers' reduction potential was measured at -0.58 and $-0.60 \mathrm{~V}$ for 3-NP and 4-NP, respectively. The APGE exhibited redox peaks at $0.12 / 0.10 \mathrm{~V}$ and $-0.01 /-0.03 \mathrm{~V}$ with a calculated $\Delta \mathrm{Ep}$ of $0.02 \mathrm{~V}$ and $0.02 \mathrm{~V}$. In addition, the reduction of nitrophenols was observed at -0.55 and $-0.64 \mathrm{~V}$ for 3-NP and 4-NP, respectively. Finally, APGE/PTH coated electrode redox potential was measured at $0.07 / 0.08 \mathrm{~V}$ and $-0.04 /-0.05 \mathrm{~V}$ with calculated $\Delta \mathrm{Ep}$ of 0.01 and $0.01 \mathrm{~V}$, respectively. Reduction of these nitrophenols was observed in the potential of -0.52 and $-0.61 \mathrm{~V}$ for 3-NP and 4-NP, respectively. This cyclic voltammetry result indicates that redox reactions were reversible for both APGE and APGE/PTH while the unmodified PGE was quasi-reversible towards sensing of 3-NP and 4-NP. However, compared to other electrodes, the APGE/PTH coated electrode showed excellent electrocatalytic behavior towards sensing of 3-NP and 4-NP.

\subsection{Electrocatalytic Mechanism towards 3-NP and 4-NP}

The electrocatalytic sensing of 3-NP and 4-NP for the voltammetric signal peak-topeak separation can be explained by different routes. Initially, PTH behaves as an electron transfer mediating material [59] to improve electron transfer kinetics for the catalytic reduction of 3-NP and 4-NP by following

$$
\begin{aligned}
& 3-\mathrm{NP}(\mathrm{o})+\mathrm{PTH}(\mathrm{r}) \rightarrow 3-\mathrm{NP}(\mathrm{r})+\mathrm{PTH}(\mathrm{o}) \\
& 4-\mathrm{NP}(\mathrm{o})+\mathrm{PTH}(\mathrm{r}) \rightarrow 4-\mathrm{NP}(\mathrm{r})+\mathrm{PTH}(\mathrm{o})
\end{aligned}
$$

While the potential cycling is in the negative direction, the PTH has reduced and become catalytically active to reduce 3-NP and 4-NP. In the next step, PTH has untied $\mathrm{NH}_{2}$ moiety which can make hydrogen linkage with hydroxides moieties of 3-NP and 4-NP. This step significantly donates flagging the -OH linkage to enable the electron transfer via $\mathrm{O}-\mathrm{H}-\mathrm{N}$ bond formation [60]. Figure 3C illustrates the sensing mechanism of 3-NP and 4-NP via hydrogen linkage. It clearly shows that the particular electron transfer kinetics are quite equal for 3-NP and 4-NP due to their different skeletal properties. While, 3-NP and 4-NP -OH groups easily participate in hydrogen bonding, it is not relevant for 2-NP, as 2-NP undergoes intramolecular hydrogen bonding through $-\mathrm{OH}$ and $\mathrm{NO}_{2}$ groups. Therefore, the peak currents of these two nitrophenol isomers exhibit higher catalytic current. The enhanced catalytic nature for the simultaneous sensing of 3-NP and 4-NP was accredited partially to the electrostatic interactivity within the surface of PTH and nitrophenol isomers with dissimilar $\mathrm{pKa}$ values. The 3-NP $(\mathrm{pKa}=8.36)$ and $4-\mathrm{NP}(\mathrm{pKa}=7.15)$ isomers existed in the form of protonation at $\mathrm{pH}-7$.

\section{6. $p H$ Influence}

The influence of the electrolyte $\mathrm{pH}$ on the sensing of 3-NP and 4-NP using APGE/PTH was studied in the $\mathrm{pH}$ range from 3 to 9 , and the obtained voltammetric outputs are displayed in Figure 4A. The cathodic currents of 3-NP and 4-NP were raised slowly with the increase in $\mathrm{pH}$ from 3 to 7 (Figure $4 \mathrm{~B}$ ). Over $\mathrm{pH} 7$, the cathodic current gradually reduced in the $\mathrm{pH}$ range from 8 to 9 . This cathodic peak current decreases due to the protonated form of the amine group $\left(-\mathrm{NH}_{3}{ }^{+}\right)$of nitrogen on the $\mathrm{PTH}$ at lower $\mathrm{pH}$ [37]. While increasing the $\mathrm{pH}$, the creation of $\mathrm{NH}_{3}{ }^{+}$gradually decreases and excess protic aromatic compounds are produced. The 3-NP and 4-NP can connect with the nitrogen atoms present on the PTH polymer. However, the cathodic peak current was enhanced with the higher $\mathrm{pH}$ condition from 3 to 7, whereas at neutral $\mathrm{pH}$ (PBS-7), 3-NP and 4-NP become the deprotonated form of anions, and they are ready for the reduction process [12]. Meanwhile, PTH containing nitrogen atoms may become deprotonated and produce negative charge at high $\mathrm{pH}$ conditions. Hence, the electrostatic repulsion between the target 3-NP/4-NP and the surface of the electrode might be one of the main reasons for the decrease in the peak current of these analytes in the $\mathrm{pH}$ range from 8 to 9 . In addition, the relation between $\mathrm{pH}$ and the cathodic potential of 3-NP and 4-NP was studied and the results are shown 
in Figure 4C. In Figure 4C, the cathodic peak potential has shifted towards the cathodic direction in the $\mathrm{pH}$ range from 3 to 9 for both analytes. The linear regression equation of the cathodic peak potential with the $\mathrm{pH}$ for these analytes are $\mathrm{Epc}=-57 \mathrm{pH}+367 \mathrm{mV}$ $\left(\mathrm{R}^{2}=0.9926\right)$ and $\mathrm{Epc}=-58 \mathrm{pH}+229 \mathrm{mV}\left(\mathrm{R}^{2}=0.9963\right)$ for 3-NP and 4-NP, respectively. Both calibration lines were almost equal, which might explain why the peak potential of 3-NP and 4-NP are almost constant. From the calibration plots, slope values from the equation suggest that the electron transfer on the surface of the electrode is an equal number of protons that were coupled with an equal number of electrons that were transferred [12]. Hence, to attain high sensitivity, pH-7 (PBS) was chosen for simultaneous sensing of 3-NP and 4-NP.
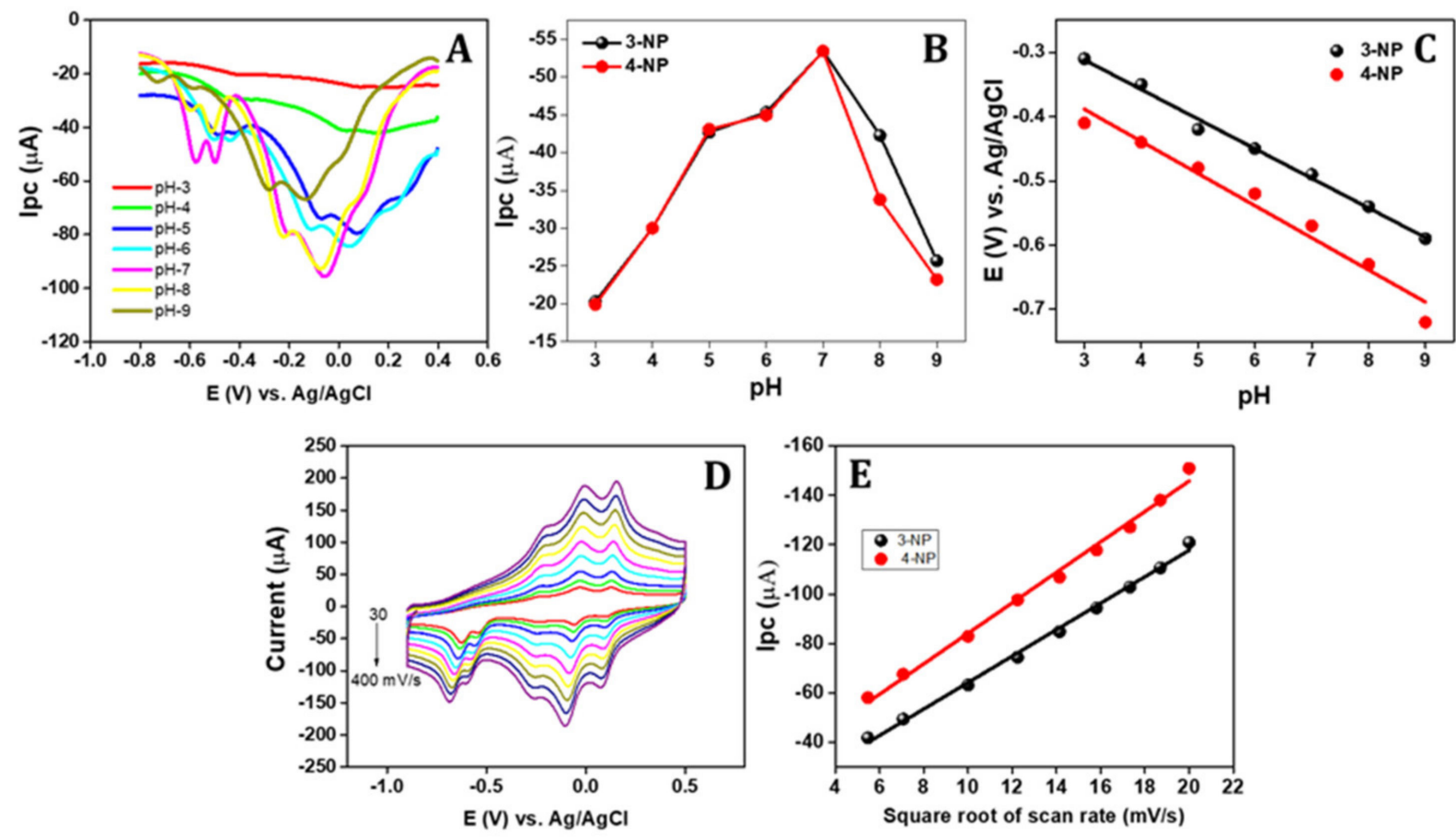

Figure 4. (A) Influence of different $\mathrm{pH}$ condition ( $\mathrm{pH}-3$ to $\mathrm{pH}-9)$ on sensing $(20 \mu \mathrm{M})$ of 3-NP and 4-NP; (B) the relationship between $\mathrm{pH}$ vs. cathodic peak current of both 3-NP and 4-NP; (C) the relationship between $\mathrm{pH}$ vs. cathodic potential shift of both 3-NP and 4-NP; (D) the influence of different scan rates (30 to $400 \mathrm{mV} / \mathrm{s}$ ) in the presence of $20 \mu \mathrm{M}$ of 3-NP and 4-NP in $0.1 \mathrm{M}$ PBS; and (E) the relationship between the square root of scan rate vs. cathodic peak current of 3-NP and 4-NP.

\subsection{Scan Rate Influence}

The scan rate influence on the electrocatalytic sensing of 3-NP and 4-NP were studied using the APGE/PTH electrode. From Figure 4D, the reduction peak potential of 3-NP and 4-NP were shifted to the positive side, even while increasing the scan rate from 30 to $400 \mathrm{mV} / \mathrm{s}$. The cathodic current of 3-NP and 4-NP increased with the increasing scan rate. The cathodic peak current of these analytes was directly proportional to the square root of scan rate (Figure $4 \mathrm{E}$ ) and the linear regression equation is Epc $=-5.35 \mathrm{~V}+10.55$ $\left(\mathrm{R}^{2}=0.9957\right)$ and $\mathrm{Epc}=-6.17 \mathrm{~V}+22.39\left(\mathrm{R}^{2}=0.9927\right)$ for $3-\mathrm{NP}$ and $4-\mathrm{NP}$, respectively. Hence, these results suggest that the electrode reaction is a diffusion-controlled process [34,61].

No absorption of 3-NP and 4-NP on the APGE/PTH electrode was observed. To confirm this phenomenon, the cyclic voltammetry for the 3-NP and 4-NP sensing in PBS solution at successful cycles was studied. The voltammogram results show that the cathodic peak current remained constant while repeating the cyclic voltammograms. These results clearly suggest that there is no absorption of 3-NP and 4-NP on the surface of the electrode. 


\subsection{Simultaneous DPV Method Sensing of 3-NP and 4-NP}

Based on the previous experimental results, the APGE/PTH electrode is proposed for the sensing of 3-NP and 4-NP, which can be detected independently and simultaneously via the differential pulse voltammetry technique. Figure $5 \mathrm{~A}$ illustrates the differential pulse voltammogram of the different quantities of nitrophenol isomers. From the voltammograms it can be seen that the reduction potential of 3-NP sensing is at $-0.47 \mathrm{~V}$ and the cathodic current increases linearly with the increasing concentration of 3-NP. Figure 5B shows the obtained linear concentration ranges from 20 to $330 \mathrm{nM}$ with the linear regression equation of $i p c=-23.99(3-\mathrm{NP})+0.263\left(\mathrm{R}^{2}=0.999\right)$ and a calculated LOD $(\mathrm{S} / \mathrm{N}=3)$ of $5 \mathrm{nM}$, with the reduction potential of $4-\mathrm{NP}$, measured at $-0.56 \mathrm{~V}$, remaining significantly unchanged. A similar procedure was followed for 4-NP detection and the results are displayed in Figure 5C. The obtained wide concentrations ranging from 15 to $330 \mathrm{nM}$ with linear regression equation of $i p c=-18.35(4-\mathrm{NP})+0.282\left(\mathrm{R}^{2}=0.998\right)$ and a calculated LOD of $4 \mathrm{nM}$, without any interference with 3-NP (Figure 5D). The simultaneous sensing of these two nitrophenol isomers was tested and the results are displayed in Figure 6A. The DPV responses of both 3-NP and 4-NP were sensed simultaneously in concentrations ranging from 20 to $230 \mathrm{nM}$ and 15 to $280 \mathrm{nM}$ (Figure 6B,C) with ipc $=-22.67(3-\mathrm{NP})+0.275$ $\left(\mathrm{R}^{2}=0.996\right)$ and $i p c=-21.86(4-\mathrm{NP})+0.278\left(\mathrm{R}^{2}=0.988\right)$, and calculated LODs of $4.5 \mathrm{nM}$ and $4 \mathrm{nM}$ and sensitivities of $22.45 \mu \mathrm{A} / \mathrm{nM} \mathrm{cm}^{2}$ and $27.12 \mu \mathrm{A} / \mathrm{nM} \mathrm{cm}^{2}$ for 3-NP and 4-NP, respectively. The analytical parameters of the developed sensor for simultaneous sensing of 3-NP and 4-NP were compared with results from earlier published works $[1,15,17,34,62-64]$ and the comparison is displayed in Table 1.
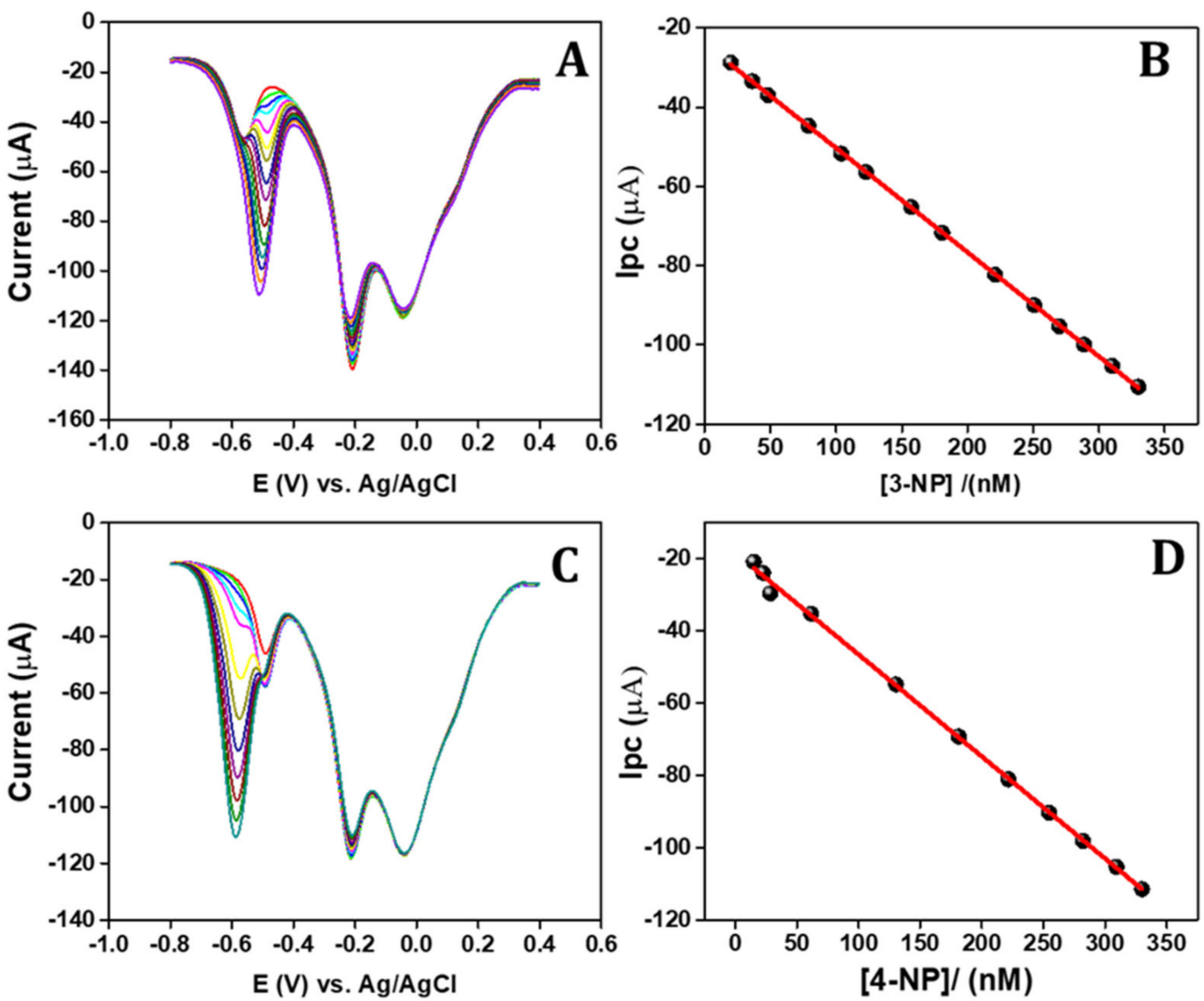

Figure 5. (A) DPV response of the APGE/PTH in different concentrations of 3-NP in the presence of $20 \mathrm{nM}$ of 4-NP; (B) 3-NP concentration vs. cathodic peak current calibration plot; (C) DPV response of 4-NP at different concentrations in the presence of $20 \mathrm{nM}$ of 3-NP; and (D) 4-NP concentration vs. cathodic peak current calibration plot. 

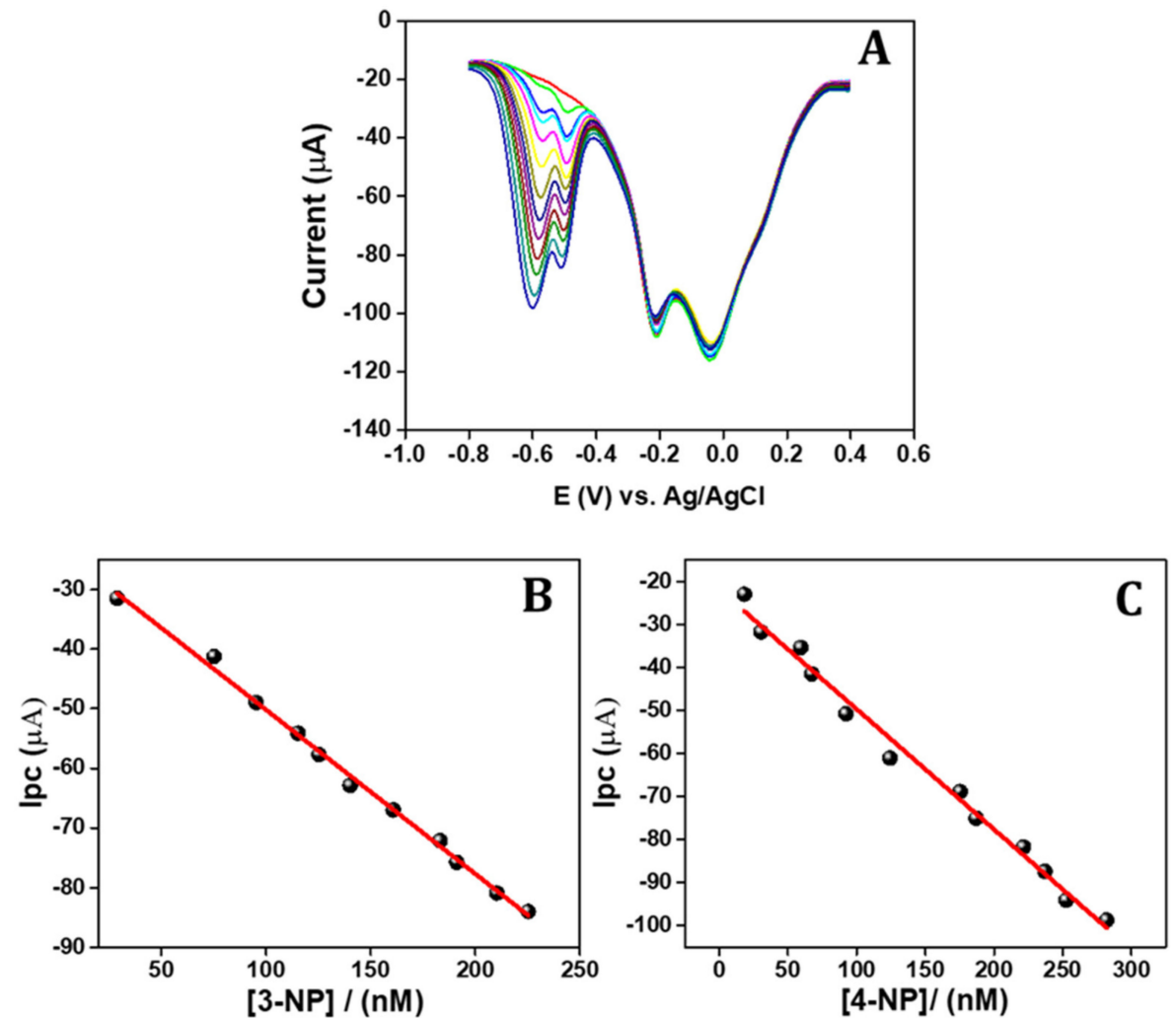

Figure 6. (A) DPV response of simultaneous sensing of 3-NP and 4-NP in various concentrations at $0.1 \mathrm{M}$ PBS and (B,C) 3-NP and 4-NP concentration and corresponding cathodic current response calibration plot.

Table 1. Analytical parameters comparison studies of the APGE/PTH with other reported electrodes.

\begin{tabular}{|c|c|c|c|c|c|}
\hline Modified Electrode & Technique & Analytical Parameter & 3-NP & 4-NP & Ref \\
\hline \multirow{2}{*}{ APGE/PTH } & \multirow{2}{*}{ DPV } & Linear range (nmol/L) & $20-230$ & $15-280$ & \multirow{2}{*}{ Proposed work } \\
\hline & & $\mathrm{LOD}(\mathrm{nmol} / \mathrm{L})$ & 4.5 & 4 & \\
\hline \multirow{2}{*}{ Polyfurfural/GCE } & \multirow{2}{*}{ DPV } & Linear range $(\mathrm{mol} / \mathrm{L})$ & $750-100,000$ & $750-100,000$ & \multirow{2}{*}{ [1] } \\
\hline & & $\mathrm{LOD}(\mathrm{nmol} / \mathrm{L})$ & 50 & 40 & \\
\hline \multirow{2}{*}{$\mathrm{PSF} / \mathrm{GCE}$} & \multirow{2}{*}{ DPV } & Linear range (nmol/L) & $200-100,000$ & $100-120,000$ & \multirow{2}{*}{ [17] } \\
\hline & & LOD (nmol/L) & & & \\
\hline \multirow{2}{*}{$\left(\mathrm{Fe}_{3} \mathrm{O}_{4}-\mathrm{Pt} \mathrm{NPs}\right) / \mathrm{GCE}$} & \multirow{2}{*}{ DPV } & Linear range (nmol/L) & $100-1500$ & $100-1500$ & \multirow{2}{*}{ [15] } \\
\hline & & LOD (nmol/L) & 45.3 & 48.2 & \\
\hline \multirow{2}{*}{ CalCOP-MPC/GCE } & \multirow{2}{*}{ DPV } & Linear range (nmol/L) & $1000-400,000$ & $1000-400,000$ & \multirow{2}{*}[34]{} \\
\hline & & LOD (nmol/L) & 122 & 212 & \\
\hline \multirow{2}{*}{ SBCD-rGO/GCE } & \multirow{2}{*}{ DPV } & Linear range (nmol/L) & $100-800,000$ & $100-800,000$ & \multirow{2}{*}{ [17] } \\
\hline & & LOD (nmol/L) & 30 & 50 & \\
\hline \multirow{2}{*}{ OMCs/GCE } & \multirow{2}{*}{ DPV } & Linear range (nmol/L) & $1000-100,000$ & $2000-90,000$ & \multirow{2}{*}{ [62] } \\
\hline & & LOD (nmol/L) & 60 & 100 & \\
\hline \multirow{2}{*}{ PTTB/GCE } & \multirow{2}{*}{ DPV } & Linear range (nmol/L) & $300-12,500$ & $300-15,000$ & \multirow{2}{*}{ [63] } \\
\hline & & $\mathrm{LOD}(\mathrm{nmol} / \mathrm{L})$ & 50 & 50 & \\
\hline \multirow{2}{*}{ Poly(p-ABSA)/GCE } & \multirow{2}{*}{ DPV } & Linear range (nmol/L) & $3000-800,000$ & $3000-800,000$ & \multirow{2}{*}[64]{} \\
\hline & & $\mathrm{LOD}(\mathrm{nmol} / \mathrm{L})$ & 500 & 300 & \\
\hline
\end{tabular}




\subsection{Selectivity of the APGE/PTH}

The common interference species for the simultaneous sensing of 3-NP and 4-NP were tested. Structurally similar molecules such as hydroquinone, resorcinol, 2-nitrophenol, phenol, and catechol were tested with the APGE/PTH electrode. No significant peak current was observed for resorcinol, catechol, hydroquinone, and phenol in the current operating potential range $(0.4$ to $-0.8 \mathrm{~V})$, and only a small hump was observed with 2-nitrophenol $(200 \mu \mathrm{mol} / \mathrm{L})$, the cathodic potential of which was measured at $-0.42 \mathrm{~V}$. This small hump might be due to the interaction between 2-nitrophenol and the electrode surface (repulsion). Therefore, these phenolic compounds' coexistence does not affect the simultaneous sensing of 3-NP and 4-NP. Subsequently, the most common interfering ions, such as $\mathrm{NH}_{4}{ }^{+}, \mathrm{Ca}^{2+}, \mathrm{Mg}^{2+}, \mathrm{Fe}^{2+}, \mathrm{NO}^{3-}, \mathrm{Zn}^{2+}, \mathrm{SO}_{4}{ }^{2-}$, and citrate ions were tested at up to 100 -fold excess concentration and no significant cathodic peak disturbances were observed. Hence, this interference study clearly showed that the simultaneous sensing of 3-NP and 4-NP is very reliable at ambient temperature and conditions.

\subsection{Stability and Reproducibility of the APGE/PTH}

Stability and reproducibility are significant key parameters of the proposed APGE/PTH sensing of 3-NP and 4-NP. The fabricated APGE/PTH electrode was studied by exposing it to different conditions to access its long-term performance and shelf life. The electrode was kept in an air-tight container at room temperature when not in use. The APGE/PTH electrode sensing of 3-NP and 4-NP in 0.1 M PBS was tested by parallel observation of the reduction current in each 3-day interval. The DPV response of the proposed electrode towards sensing of 3-NP and 4-NP in different intervals is shown in Figure S3. From the DPV response measured at different intervals, the proposed APGE/PTH showed stable current response while sensing 3-NP and 4-NP. The proposed electrode current response of these nitrophenol isomers retained $92.12 \%$ and $94.34 \%$ (from the initial current) after 60 days. These results indicate that the proposed electrode has high stability. Moreover, the proposed electrode was successfully examined for reproducibility by testing the six different electrodes under the same conditions. The RSD was $4.12 \%$ and $3.99 \%$ for $3-\mathrm{NP}$ and 4-NP, respectively. The APGE/PTH electrode was stored in an air-tight container while not in use. Therefore, these analytical results suggest that the fabricated APGE/PTH electrode is a promising material for sensing nitrophenols with notable stability and reproducibility.

\subsection{Real Sample Studies}

The practical utility of the fabricated APGE/PTH for the simultaneous sensing of 3-NP and 4-NP in different environmental waters. Lab tap water, lake water, and river water samples were tested for the quantitative measurements. The standard addition method was used for the estimation of environmental water samples. The water samples were initially purified by using $0.45 \mu \mathrm{M}$ cellulose filter paper followed by adjusting the $\mathrm{pH}$ of the filtered solution to $\mathrm{pH}-7$ to match the PBS used earlier in the testing. Three similar measurements are studied for the detection of these nitrophenol isomers. All the obtained analytical results were collected and displayed in Table 2 . The average recovery was found to be from $98.16 \%$ to $103.43 \%$. These results indicate that this proposed protocol can be effectively used for the simultaneous sensing of 3-NP and 4-NP in environmental water samples.

Table 2. Estimation of 3-NP and 4-NP in different environmental water samples.

\begin{tabular}{|c|c|c|c|c|c|c|c|c|c|}
\hline \multirow{2}{*}{ Samples } & \multirow{2}{*}{$\begin{array}{c}\text { Initial } \\
\text { Conc. }\end{array}$} & \multicolumn{2}{|c|}{ Added (nmol/L) } & \multicolumn{2}{|c|}{ Observed (nmol/L) } & \multicolumn{2}{|c|}{ Recovery (\%) } & \multicolumn{2}{|c|}{ RSD (\%) } \\
\hline & & 3-NP & 4-NP & 3-NP & $4-\mathrm{NP}$ & 3-NP & 4-NP & 3-NP & 4-NP \\
\hline \multirow[b]{2}{*}{ Tap water } & \multirow[b]{2}{*}{ NS * } & 30.0 & 20.0 & $\begin{array}{c}30.07 \\
( \pm 0.05)\end{array}$ & $\begin{array}{c}19.89 \\
( \pm 0.03)\end{array}$ & 100.23 & 99.45 & 2.19 & 1.98 \\
\hline & & 50.0 & 50.0 & $\begin{array}{c}49.78 \\
( \pm 0.08)\end{array}$ & $\begin{array}{c}50.07 \\
( \pm 0.01)\end{array}$ & 99.56 & 100.14 & 2.32 & 2.14 \\
\hline
\end{tabular}


Table 2. Cont.

\begin{tabular}{|c|c|c|c|c|c|c|c|c|c|}
\hline \multirow{2}{*}{ Samples } & \multirow{2}{*}{$\begin{array}{c}\text { Initial } \\
\text { Conc. }\end{array}$} & \multicolumn{2}{|c|}{ Added (nmol/L) } & \multicolumn{2}{|c|}{ Observed (nmol/L) } & \multicolumn{2}{|c|}{ Recovery (\%) } & \multicolumn{2}{|c|}{ RSD (\%) } \\
\hline & & 3-NP & $4-\mathrm{NP}$ & 3-NP & 4-NP & 3-NP & 4-NP & 3-NP & 4-NP \\
\hline & & 100.0 & 100.0 & $\begin{array}{c}99.85 \\
( \pm 0.03)\end{array}$ & $\begin{array}{c}100.08 \\
( \pm 0.07)\end{array}$ & 99.85 & 100.08 & 2.18 & 2.21 \\
\hline \multirow{3}{*}{ Lake water } & \multirow{3}{*}{ NS * } & 30.0 & 20.0 & $\begin{array}{c}30.09 \\
( \pm 0.08)\end{array}$ & $\begin{array}{c}20.07 \\
( \pm 0.01)\end{array}$ & 100.30 & 100.35 & 1.87 & 1.56 \\
\hline & & 50.0 & 50.0 & $\begin{array}{c}51.01 \\
( \pm 0.05)\end{array}$ & $\begin{array}{c}49.08 \\
( \pm 0.08)\end{array}$ & 102.02 & 98.16 & 1.98 & 1.23 \\
\hline & & 100.0 & 100.0 & $\begin{array}{c}99.03 \\
( \pm 0.01)\end{array}$ & $\begin{array}{c}100.10 \\
( \pm 0.03)\end{array}$ & 99.03 & 100.10 & 3.23 & 3.18 \\
\hline \multirow{3}{*}{ River water } & \multirow{3}{*}{ NS * } & 30.0 & 20.0 & $\begin{array}{c}31.03 \\
( \pm 0.09)\end{array}$ & $\begin{array}{c}20.08 \\
( \pm 0.03)\end{array}$ & 103.43 & 100.40 & 1.89 & 1.34 \\
\hline & & 50.0 & 50.0 & $\begin{array}{c}49.96 \\
( \pm 0.05)\end{array}$ & $\begin{array}{c}50.65 \\
( \pm 0.08)\end{array}$ & 99.92 & 101.30 & 2.33 & 2.12 \\
\hline & & 100.0 & 100.0 & $\begin{array}{c}99.82 \\
( \pm 0.02)\end{array}$ & $\begin{array}{c}100.08 \\
( \pm 0.07)\end{array}$ & 99.82 & 100.08 & 3.16 & 3.26 \\
\hline
\end{tabular}

* NS-not sensing (below the detection limit).

\section{Conclusions}

A very sensitive, robust, and facile electroanalytical technique for the simultaneous sensing of 3-NP and 4-NP was developed using APGE/PTH. The modified electrode preparation steps were very simple compared with other electrode preparation protocols. APGE/PTH showed well-defined redox peaks in the sensing of 3-NP and 4-NP in cyclic voltammetry with a potential difference of $0.09 \mathrm{mV}$ between 3-NP and 4-NP, a sufficient potential range for the simultaneous sensing of nitrophenol isomers. The possible sensing mechanism and the voltammetric signal separations of these 3-NP and 4-NP on the APGE/PTH have been discussed. The enhanced electrocatalytic property and reversible electron transfer of the redox reaction of 3-NP and 4-NP were achieved on the APGE/PTH electrode. Finally, the proposed electrode exhibited high sensitivity, with a low detection limit being achieved. Furthermore, the real-time utility of the fabricated sensor was tested in different environmental water samples with satisfactory recovery results.

Supplementary Materials: The following supporting information can be downloaded at: https: / / www.mdpi.com/article/10.3390/s22031151/s1. Figure S1: Photograph of a 4-HB graphite pencil, Figure S2: Electrochemical polymerization of thionine on APGE surface in 0.1 M PBS electrolyte at scan rate of $50 \mathrm{mV} / \mathrm{s}$ for 30 segments and Figure S3: Stability studies of APGE/PTH towards simultaneous sensing of 3-NP and 4-NP.

Author Contributions: Conceptualization, methodology, formal analysis, investigation, writingoriginal draft preparation, V.G.S.; writing - review and editing, supervision, funding acquisition, J.I.S. and H.I. All authors have read and agreed to the published version of the manuscript.

Funding: This work was supported by the National Research Foundation (NRF) of Korea (grant no. 2021R1A2B5B01001796, 2019R1I1A1A01048852, 2021R1F1A1062528, and 2021R1A4A5031805) and the Technology Innovation Program (grant no. 20013597) funded by the Ministry of Trade, Industry \& Energy.

Institutional Review Board Statement: Not applicable.

Informed Consent Statement: Not applicable.

Data Availability Statement: Not applicable.

Conflicts of Interest: The authors declare no conflict of interest. The funders had no role in the design of the study; in the collection, analyses, or interpretation of data; in the writing of the manuscript; or in the decision to publish the results. 


\section{References}

1. Wei, T.; Huang, X.; Zeng, Q.; Wang, L. Simultaneous electrochemical determination of nitrophenol isomers with the polyfurfural film modified glassy carbon electrode. J. Electroanal. Chem. 2015, 743, 105-111. [CrossRef]

2. Zhang, X.-D.; Zhao, Y.; Chen, K.; Guo, J.; Wang, P.; Wu, H.; Sun, W.-Y. Cucurbit[6]uril-based supramolecular assemblies incorporating metal complexes with multiaromatic ligands as structure-directing agent for detection of aromatic amines and nitroaromatic compounds. Sens. Actuators B Chem. 2018, 282, 844-853. [CrossRef]

3. Shi, L.; Yin, Y.; Zhang, L.-C.; Wang, S.; Sillanpää, M.; Sun, H. Design and engineering heterojunctions for the photoelectrochemical monitoring of environmental pollutants: A review. Appl. Catal. B Environ. 2019, 248, 405-422. [CrossRef]

4. Ramalingam, M.; Ponnusamy, V.K.; Sangilimuthu, S.N. Electrochemical determination of 4-nitrophenol in environmental water samples using porous graphitic carbon nitride-coated screen-printed electrode. Environ. Sci. Pollut. Res. 2019, $27,17481-17491$. [CrossRef] [PubMed]

5. El Mhammedi, M.; Achak, M.; Bakasse, M.; Chtaini, A. Electrochemical determination of para-nitrophenol at apatite-modified carbon paste electrode: Application in river water samples. J. Hazard. Mater. 2009, 163, 323-328. [CrossRef] [PubMed]

6. Li, J.; Kuang, D.; Feng, Y.; Zhang, F.; Xu, Z.; Liu, M. A graphene oxide-based electrochemical sensor for sensitive determination of 4-nitrophenol. J. Hazard. Mater. 2012, 201-202, 250-259. [CrossRef] [PubMed]

7. Xu, G.; Yang, L.; Zhong, M.; Li, C.; Lu, X.; Kan, X. Selective recognition and electrochemical detection of p-nitrophenol based on a macroporous imprinted polymer containing gold nanoparticles. Microchim. Acta 2013, 180, 1461-1469. [CrossRef]

8. Gong, S.; Xiao, X.; Sam, D.K.; Liu, B.; Wei, W.; Yu, W.; Lv, X. Dispersed copper nanoparticles promote the electron mobility of nitrogen-rich graphitized carbon aerogel for electrochemical determination of 4-nitrophenol. Microchim. Acta 2019, $186,853$. [CrossRef]

9. Luo, S.; Miao, Y.; Guo, J.; Sun, X.; Yan, G. Phosphorimetric determination of 4-nitrophenol using mesoporous molecular imprinting polymers containing manganese(II)-doped ZnS quantum dots. Microchim. Acta 2019, 186, 249. [CrossRef]

10. Xu, G.; Li, B.; Wang, X.; Luo, X. Electrochemical sensor for nitrobenzene based on carbon paste electrode modified with a poly(3,4-ethylenedioxythiophene) and carbon nanotube nanocomposite. Microchim. Acta 2014, 181, 463-469. [CrossRef]

11. Wijker, R.S.; Kurt, Z.; Spain, J.C.; Bolotin, J.; Zeyer, J.; Hofstetter, T.B. Isotope Fractionation Associated with the Biodegradation of 2- and 4-Nitrophenols via Monooxygenation Pathways. Environ. Sci. Technol. 2013, 47, 14185-14193. [CrossRef]

12. Murphy, M.; Manoj, D.; Saravanakumar, D.; Thenmozhi, K.; Senthilkumar, S. Water insoluble, self-binding viologen functionalized ionic liquid for simultaneous electrochemical detection of nitrophenol isomers. Anal. Chim. Acta 2020, 1138, 89-98. [CrossRef] [PubMed]

13. Kubendhiran, S.; Sakthivel, R.; Chen, S.-M.; Mutharani, B.; Chen, T.-W. Innovative Strategy Based on a Novel Carbon-Black- $\beta$ Cyclodextrin Nanocomposite for the Simultaneous Determination of the Anticancer Drug Flutamide and the Environmental Pollutant 4-Nitrophenol. Anal. Chem. 2018, 90, 6283-6291. [CrossRef] [PubMed]

14. Umar, A.; Kim, S.; Kumar, R.; Algarni, H.; Al-Assiri, M.S. Platinum nanoparticles decorated carbon nanotubes for highly sensitive 2-nitrophenol chemical sensor. Ceram. Int. 2016, 42, 9257-9263. [CrossRef]

15. Gerent, G.G.; Spinelli, A. Magnetite-platinum nanoparticles-modified glassy carbon electrode as electrochemical detector for nitrophenol isomers. J. Hazard. Mater. 2017, 330, 105-115. [CrossRef]

16. Ni, Y.; Wang, L.; Kokot, S. Simultaneous determination of nitrobenzene and nitro-substituted phenols by differential pulse voltammetry and chemometrics. Anal. Chim. Acta 2001, 431, 101-113. [CrossRef]

17. Fang, Y.; Wang, D.; Lv, X.; Xu, X.; Zhou, H.; Liu, P.; Cui, B.; Wang, L. Simultaneous electrochemical determination of nitrophenol isomers Based on spirofluorene-based microporous polymer film modified electrodes through one-step electropolymerization strategy. Sens. Actuators B Chem. 2021, 333, 129568. [CrossRef]

18. Doan, V.-D.; Phan, T.L.; Le, V.T.; Vasseghian, Y.; Evgenievna, L.O.; Tran, D.L.; Le, V.T. Efficient and fast degradation of 4nitrophenol and detection of Fe(III) ions by Poria cocos extract stabilized silver nanoparticles. Chemosphere 2022, $286,131894$. [CrossRef]

19. Kumar, S.; Sekar, S.; Kaliamurthy, A.K.; Lee, S. Bifunctional rGO-NiCo2S4 MOF hybrid with high electrochemical and catalytic activity for supercapacitor and nitroarene reduction. J. Mater. Res. Technol. 2021, 12, 2489-2501. [CrossRef]

20. Karaová, J.; Barek, J.; Schwarzová-Pecková, K. Oxidative and Reductive Detection Modes for Determination of Nitrophenols by High-Performance Liquid Chromatography with Amperometric Detection at a Boron Doped Diamond Electrode. Anal. Lett. 2016, 49, 66-79. [CrossRef]

21. Belloli, R.; Barletta, B.; Bolzacchini, E.; Meinardi, S.; Orlandi, M.; Rindone, B. Determination of toxic nitrophenols in the atmosphere by high-performance liquid chromatography. J. Chromatogr. A 1999, 846, 277-281. [CrossRef]

22. Zhang, H.; Wang, M.; Zhao, J.; Shi, Z. Sandwich-type spontaneous injection of nitrophenols for capillary electrophoresis analysis. Anal. Methods 2012, 4, 2177-2182. [CrossRef]

23. Miró, M.; Cladera, A.; Estela, J.M.; Cerdà, V. Dual wetting-film multi-syringe flow injection analysis extraction: Application to the simultaneous determination of nitrophenols. Anal. Chim. Acta 2001, 438, 103-116. [CrossRef]

24. Ahmed, G.H.G.; Laíño, R.B.; Calzón, J.A.G.; García, M.E.D. Highly fluorescent carbon dots as nanoprobes for sensitive and selective determination of 4-nitrophenol in surface waters. Mikrochim. Acta 2015, 182, 51-59. [CrossRef]

25. Wang, F.; Fu, X.; Chai, X.; Han, Q.; Wang, H.; Hao, Q. Highly selective fluorometric detection of para-nitrophenol from its isomers by nitrogen-doped graphene quantum dots. Microchem. J. 2021, 168, 106389. [CrossRef] 
26. Ashok Kumar, E.; Riswana Barveen, N.; Wang, T.-J.; Kokulnathan, T.; Chang, Y.-H. Development of SERS platform based on ZnO multipods decorated with Ag nanospheres for detection of 4-nitrophenol and rhodamine 6G in real samples. Microchem. J. 2021, 170, 106660. [CrossRef]

27. Liu, J.; Chen, H.; Lin, Z.; Lin, J.-M. Preparation of Surface Imprinting Polymer Capped Mn-Doped ZnS Quantum Dots and Their Application for Chemiluminescence Detection of 4-Nitrophenol in Tap Water. Anal. Chem. 2010, 82, 7380-7386. [CrossRef]

28. Delnavaz, E.; Amjadi, M. An ultrasensitive chemiluminescence assay for 4-nitrophenol by using luminol-NaIO4 reaction catalyzed by copper, nitrogen co-doped carbon dots. Spectrochim. Acta Part A Mol. Biomol. Spectrosc. 2020, 241, 118608. [CrossRef]

29. Ramalingam, M.; Kokulnathan, T.; Tsai, P.-C.; Valan Arasu, M.; Al-Dhabi, N.A.; Prakasham, K.; Ponnusamy, V.K. Ultrasonicationassisted synthesis of gold nanoparticles decorated ultrathin graphitic carbon nitride nanosheets as a highly efficient electrocatalyst for sensitive analysis of caffeic acid in food samples. Appl. Nanosci. 2021. [CrossRef]

30. Kaya, H.O.; Cetin, A.E.; Azimzadeh, M.; Topkaya, S.N. Pathogen detection with electrochemical biosensors: Advantages, challenges and future perspectives. J. Electroanal. Chem. 2021, 882, 114989. [CrossRef]

31. Liu, G.; Xiong, Z.; Yang, L.; Shi, H.; Fang, D.; Wang, M.; Shao, P.; Luo, X. Electrochemical approach toward reduced graphene oxide-based electrodes for environmental applications: A review. Sci. Total Environ. 2021, 778, 146301. [CrossRef] [PubMed]

32. Hashim, H.S.; Fen, Y.W.; Omar, N.A.S.; Fauzi, N.I.M. Sensing Methods for Hazardous Phenolic Compounds Based on Graphene and Conducting Polymers-Based Materials. Chemosensors 2021, 9, 291. [CrossRef]

33. Hui, Y.; Bian, C.; Xia, S.; Tong, J.; Wang, J. Synthesis and electrochemical sensing application of poly (3, 4-ethylenedioxythiophene)based materials: A review. Anal. Chim. Acta 2018, 1022, 1-19. [CrossRef] [PubMed]

34. Ding, Z.; Zhao, J.; Hao, Z.; Guo, M.; Li, L.; Li, N.; Sun, X.; Zhang, P.; Cui, J. Simultaneous electrochemical determination of nitrophenol isomers based on macroporous carbon functionalized with amino-bridged covalent organic polycalix[4]arenes. J. Hazard. Mater. 2022, 423, 127034. [CrossRef] [PubMed]

35. Jin, G.; Huang, F.; Li, W.; Yu, S.; Zhang, S.; Kong, J. Sensitive detection of trifluoperazine using a poly-ABSA/SWNTs film-modified glassy carbon electrode. Talanta 2008, 74, 815-820. [CrossRef]

36. Jeevagan, A.J.; John, S.A. Electrochemical determination of L-methionine using the electropolymerized film of non-peripheral amine substituted $\mathrm{Cu}(\mathrm{II})$ phthalocyanine on glassy carbon electrode. Bioelectrochemistry 2012, 85, 50-55. [CrossRef]

37. Ahammad, A.J.S.; Rahman, M.; Xu, G.-R.; Kim, S.; Lee, J.-J. Highly sensitive and simultaneous determination of hydroquinone and catechol at poly(thionine) modified glassy carbon electrode. Electrochimica Acta 2011, 56, 5266-5271. [CrossRef]

38. Ge, C.-Y.; Rahman, M.; Li, X.-B.; Lee, J.-J. Simultaneous and Interference-Free Detection of Hydroquinone and Catechol on Poly (Evans Blue)-Modified Glassy Carbon Electrode. J. Electrochem. Soc. 2016, 163, B556. [CrossRef]

39. Rahman, M.; Lee, J.-J. Sensitivity control of dopamine detection by conducting poly(thionine). Electrochem. Commun. 2021, 125, 107005. [CrossRef]

40. Rahman, M.; Lopa, N.S.; Kim, Y.J.; Choi, D.-K.; Lee, J.-J. Label-Free DNA Hybridization Detection by Poly(Thionine)-Gold Nanocomposite on Indium Tin Oxide Electrode. J. Electrochem. Soc. 2016, 163, B153. [CrossRef]

41. Dalkiran, B.; Brett, C.M.A. A novel nanostructured poly(thionine)-deep eutectic solvent/CuO nanoparticle film-modified disposable pencil graphite electrode for determination of acetaminophen in the presence of ascorbic acid. Anal. Bioanal. Chem. 2021, 413, 1149-1157. [CrossRef] [PubMed]

42. Gao, Q.; Cui, X.; Yang, F.; Ma, Y.; Yang, X. Preparation of poly(thionine) modified screen-printed carbon electrode and its application to determine NADH in flow injection analysis system. Biosens. Bioelectron. 2003, 19, 277-282. [CrossRef]

43. Ghica, M.E.; Ferreira, G.M.; Brett, C.M.A. Poly(thionine)-carbon nanotube modified carbon film electrodes and application to the simultaneous determination of acetaminophen and dipyrone. J. Solid State Electrochem. 2015, 19, 2869-2881. [CrossRef]

44. Dalkıran, B.; Fernandes, I.P.G.; David, M.; Brett, C.M.A. Electrochemical synthesis and characterization of poly(thionine)-deep eutectic solvent/carbon nanotube-modified electrodes and application to electrochemical sensing. Mikrochim. Acta 2020, 187, 609. [CrossRef] [PubMed]

45. $\mathrm{Li}, \mathrm{X} . ; \mathrm{Kan}, \mathrm{X}$. A boronic acid carbon nanodots/poly(thionine) sensing platform for the accurate and reliable detection of NADH. Bioelectrochemistry 2019, 130, 107344. [CrossRef]

46. Shamspur, T.; Biniaz, Z.; Mostafavi, A.; Torkzadeh-Mahani, M.; Mohamadi, M. An Electrochemical Immunosensor Based on Poly(Thionine)-Modified Carbon Paste Electrode for the Determination of Prostate Specific Antigen. IEEE Sens. J. 2018, 18, 4861-4868. [CrossRef]

47. Xiao, Y.; Ju, H.-X.; Chen, H.-Y. A reagentless hydrogen peroxide sensor based on incorporation of horseradish peroxidase in poly(thionine) film on a monolayer modified electrode. Anal. Chim. Acta 1999, 391, 299-306. [CrossRef]

48. Wang, Q.; Zhang, H.; Wu, Y.; Yu, A. Amperometric hydrogen peroxide biosensor based on a glassy carbon electrode modified with polythionine and gold nanoparticles. Microchim. Acta 2012, 176, 279-285. [CrossRef]

49. Borisenko, K.B.; Bock, C.W.; Hargittai, I. Intramolecular Hydrogen Bonding and Molecular Geometry of 2-Nitrophenol from a Joint Gas-Phase Electron Diffraction and ab Initio Molecular Orbital Investigation. J. Phys. Chem. 1994, 98, 1442-1448. [CrossRef]

50. Kovács, A.; Keresztury, G.; Izvekov, V. Intramolecular hydrogen-bonding in 2-nitroresorcinol. A combined FT-IR, FT-Raman and computational study. Chem. Phys. 2000, 253, 193-204. [CrossRef]

51. Manikandan, R.; Deepa, P.; Narayanan, S.S. Fabrication and characterization of poly 2-napthol orange film modified electrode and its application to selective detection of dopamine. J. Solid State Electrochem. 2017, 21, 3567-3578. [CrossRef] 
52. Vishnu, N.; Kumar, A.S. A preanodized 6B-pencil graphite as an efficient electrochemical sensor for mono-phenolic preservatives (phenol and meta-cresol) in insulin formulations. Anal. Methods 2015, 7, 1943-1950. [CrossRef]

53. Nath, N.C.D.; Sarker, S.; Rahman, M.; Lee, H.J.; Kim, Y.J.; Lee, J.-J. A facile template-free chemical synthesis of poly(thionine) nanowires. Chem. Phys. Lett. 2013, 559, 56-60. [CrossRef]

54. Thangaraj, R.; Kumar, A.S. Graphitized mesoporous carbon modified glassy carbon electrode for selective sensing of xanthine, hypoxanthine and uric acid. Anal. Methods 2012, 4, 2162-2171. [CrossRef]

55. Vishnu, N.; Kumar, A.S. Development of Prussian Blue and Fe(bpy)32+ hybrid modified pencil graphite electrodes utilizing its intrinsic iron for electroanalytical applications. J. Electroanal. Chem. 2017, 786, 145-153. [CrossRef]

56. Kumar, A.S.; Shanmugam, R.; Vishnu, N.; Pillai, K.C.; Kamaraj, S. Electrochemical immobilization of ellagic acid phytochemical on MWCNT modified glassy carbon electrode surface and its efficient hydrazine electrocatalytic activity in neutral pH. J. Electroanal. Chem. 2016, 782, 215-224. [CrossRef]

57. Zen, J.-M.; Lai, Y.-Y.; Yang, H.-H.; Kumar, A.S. Multianalyte sensor for the simultaneous determination of hypoxanthine, xanthine and uric acid based on a preanodized nontronite-coated screen-printed electrode. Sens. Actuators B Chem. 2002, 84, 237-244. [CrossRef]

58. Lumibao, C.Y.; Tillekeratne, L.M.V.; Kirchhoff, J.R.; Fouchard, D.M.D.; Hudson, R.A. Electrochemical and Electrocatalytic Properties of Imidazole Analogues of the Redox Cofactor Pyrroloquinoline Quinone. Electroanal. Int. J. Devoted Fundam. Pract. Asp. Electroanal. 2008, 20, 2177-2184. [CrossRef]

59. Liu, Y.; Zhang, H.-L.; Lai, G.-S.; Yu, A.-M.; Huang, Y.-M.; Han, D.-Y. Amperometric NADH Biosensor Based on Magnetic Chitosan Microspheres/Poly(thionine) Modified Glassy Carbon Electrode. Electroanalysis 2010, 22, 1725-1732. [CrossRef]

60. Xu, Y.; Jiang, Y.; Yang, L.; He, P.-G.; Fang, Y.-Z. Direct Electrochemical Detection of Oligonucleotide Hybridization on Poly(thionine) Film. Chin. J. Chem. 2005, 23, 1665-1670. [CrossRef]

61. Huang, J.; Zhang, X.; Zhou, L.; You, T. Simultaneous electrochemical determination of dihydroxybenzene isomers using electrospun nitrogen-doped carbon nanofiber film electrode. Sens. Actuators B Chem. 2016, 224, 568-576. [CrossRef]

62. Zhang, T.; Lang, Q.; Yang, D.; Li, L.; Zeng, L.; Zheng, C.; Li, T.; Wei, M.; Liu, A. Simultaneous voltammetric determination of nitrophenol isomers at ordered mesoporous carbon modified electrode. Electrochimica Acta 2013, 106, 127-134. [CrossRef]

63. Huang, Y.; Bai, S.; Huang, J.; Ma, Y.; Zeng, Q.; Wang, M.; Wang, L. Simultaneous detection of nitrophenol isomers using an easy-to-fabricate thiophene-based microporous polymer film modified electrode. Microchem. J. 2019, 153, 104465. [CrossRef]

64. Yao, C.; Sun, H.; Fu, H.-F.; Tan, Z.-C. Sensitive simultaneous determination of nitrophenol isomers at poly(p-aminobenzene sulfonic acid) film modified graphite electrode. Electrochimica Acta 2015, 156, 163-170. [CrossRef] 